Fanum

Sociológico

\section{Forum Sociológico}

Série II

$20 \mid 2010$

A pobreza, pluralidade de olhares e de intervenções

\title{
A estruturalidade da pobreza e da exclusão social na sociedade portuguesa - conceitos, dinâmicas e desafios para a acção
}

Pedro Perista e Isabel Baptista

\section{OpenEdition}

Journals

Edição electrónica

URL: https://journals.openedition.org/sociologico/165

DOI: 10.4000/sociologico. 165

ISSN: 2182-7427

Editora

CICS.NOVA - Centro Interdisciplinar de Ciências Sociais da Universidade Nova de Lisboa

Edição impressa

Data de publição: 1 junho 2010

Paginação: $39-46$

ISSN: 0872-8380

Refêrencia eletrónica

Pedro Perista e Isabel Baptista, «A estruturalidade da pobreza e da exclusão social na sociedade portuguesa - conceitos, dinâmicas e desafios para a acção», Forum Sociológico [Online], 20 | 2010, posto online no dia 05 setembro 2012, consultado o 29 março 2022. URL: http://

journals.openedition.org/sociologico/165 ; DOl: https://doi.org/10.4000/sociologico.165

Este documento foi criado de forma automática no dia 29 março 2022.

(C) CICS.NOVA 


\title{
A estruturalidade da pobreza e da exclusão social na sociedade portuguesa - conceitos, dinâmicas e desafios para a acção
}

\author{
Pedro Perista e Isabel Baptista
}

\section{Pobreza: clarificação de um conceito}

1 O que é a pobreza? E o que é a exclusão social? Em que se diferenciam e de que forma é que se distinguem de outros conceitos, como a desigualdade, por exemplo? A complexidade destes fenómenos ajuda a explicar as diferentes perspectivas, definições e combinações que têm sido elaboradas e defendidas. Parece, porém, claro que, mais do que alternativas, as diferentes perspectivas são, na maioria das vezes, complementares, permitindo traçar um quadro menos incompleto do fenómeno, mesmo quando considerado na sua expressão individual.

2 Seja como for, parece igualmente claro que o que está em causa é o critério e o modo mais correcto de distinguir o pobre do não pobre. À primeira vista, a forma mais fácil de identificar a pobreza parece ser pelo seu lado mais visível, o das necessidades materiais. Neste caso, a tarefa consiste em escolher as necessidades materiais que interessa considerar, pelo que a pobreza corresponderá à situação em que essas necessidades ficam por satisfazer.

3 Uma outra perspectiva, inspirada no pensamento de Amartya Sen (1999), atribui importância principal a dois conceitos por ele estabelecidos: a habilitação, que permite o acesso de que os indivíduos podem dispor, e a capacidade para que estes possam funcionar e tentar encontrar as condições ideias que desejem.

4 Não se trata, porém, de uma perspectiva oposta àquelas que privilegiam as necessidades básicas, sejam estas materiais ou imateriais. 0 que a distingue é a atenção particular dada à forma e ao modo como a opção pelas necessidades em causa e a sua 
satisfação permitem ou não aos indivíduos dispor das capacidades de que necessitam para funcionar.

5 À indispensabilidade da análise da satisfação das necessidades humanas básicas juntase a análise dos meios que permitem aos indivíduos a aquisição das capacidades para funcionar e que incluem as anteriores. Por outras palavras, a satisfação das necessidades passa a ser entendida como meio e não como objectivo final.

6 É, porém, claro que, na maioria das vezes, a pobreza é definida com referência a níveis e condições de vida. Seja qual for o conceito adoptado para defini-la - absoluto, relativo ou subjectivo -, a pobreza preocupa-se com as condições que têm de ser satisfeitas, ou com os recursos que são necessários para se ter acesso a um determinado padrão de vida. Por outro lado, isto implica que se assume a existência de um limiar, abaixo do qual se estará face a uma situação de pobreza (Townsend, 1987; Machado et al., 2007; Bruto da Costa et al., 2008).

7 Do ponto de vista conceptual este é, pois, o principal factor de distinção entre a pobreza e um outro conceito - o de desigualdade -, que é, sobretudo, um conceito comparativo entre duas situações ${ }^{1}$.

8 Assim, do ponto de vista teórico, podem existir situações de altos níveis de desigualdade sem pobreza, bem como altas taxas de pobreza praticamente sem desigualdade. 0 primeiro caso ocorre quando os mais ricos estão muito acima da linha de pobreza e os mais mal situados estão pouco acima dessa linha. O segundo é o caso de uma distribuição em que os pobres estão pouco abaixo da linha de pobreza e os não pobres pouco acima da mesma linha.

9 No contexto deste artigo, a pobreza é definida como uma situação de privação por falta de recursos. Apesar da sua simplicidade, esta definição tem implicações importantes. Em primeiro lugar, implica que a pobreza abrange dois problemas: a privação e a falta de recursos².

10 Consequentemente, uma situação de privação que não seja devida à falta de recursos não é considerada como pobreza e, consequentemente, o tipo de apoio de que precisa tem a ver com o uso adequado dos seus recursos. Determinadas situações de sobreendividamento; situações decorrentes de comportamentos autodestrutivos como a toxicodependência ou de situações relacionadas com questões de natureza psiquiátrica enquadram-se nesta categoria.

11 A segunda implicação daquela definição de pobreza é a de que, para se vencer a pobreza, é necessário resolver aqueles dois problemas distintos, embora interrelacionados: a privação e a falta de recursos.

12 Não é, portanto, verdadeiro que apenas através da resolução da privação se resolva uma situação de pobreza, na medida em que fica por resolver a falta de recursos. Aliás, a maior parte das formas de resolver a privação não tem impacto sobre a falta de recursos. Mesmo em situações como o beneficiar do Rendimento Social de Inserção, por exemplo, continua a existir uma situação de dependência de meios extraordinários.

13 Deste ponto de vista, o problema da falta de recursos só fica resolvido quando a pessoa os obtém de uma das fontes que a sociedade considera como fonte normal. Consequentemente, pelo simples facto de a pobreza implicar falta de recursos, representa alguma forma de exclusão social.

14 Apesar de, como referido, a pobreza se definir, sobretudo, com referência a níveis e condições de vida, é evidente que a pobreza é, de facto, um fenómeno 
multidimensional. Essa é, aliás, uma das principais dificuldades em medi-la. A situação de falta de recursos, pela qual ela primariamente se define, está inevitavelmente ligada à consequente privação e exclusão, numa ampla gama de aspectos fundamentais da existência: condições de vida, poder, participação social, cidadania, etc.

Ao não estarem satisfeitas as suas necessidades humanas básicas, a pessoa em situação de pobreza tem, certamente, enfraquecida ou mesmo em situação de ruptura, a sua relação com diversos outros sistemas sociais, tais como o mercado de bens e serviços, o sistema de saúde, o sistema educativo, a participação política, laços sociais com amigos e com a comunidade local, etc. (Bruto da Costa, 1998). Quanto mais profunda for a privação, tanto maior será o número de sistemas sociais envolvidos e mais profundo o estado de exclusão social.

Como foi expresso por Labbens (1969): “Um homem pobre não é um homem rico com menos dinheiro; ele é outro homem. As diferenças entre um e outro não se relacionam apenas com o rendimento, também dizem respeito à educação, relações sociais, em suma, a todos os domínios da vida social: ser rico e ser pobre são dois estilos de vida."

17 Conclui-se, assim, que a pobreza representa uma forma de exclusão social, ou seja, que não existe pobreza sem exclusão social. o contrário, porém, não é válido. Com efeito, existem formas de exclusão social que não implicam pobreza. Um bom exemplo desta última situação respeita aos idosos, que, muitas vezes, são excluídos apenas por serem idosos, ou a situação de determinadas minorias étnicas e/ou culturais.

\section{Pobreza e exclusão social: uma complementaridade necessária}

Quando falamos em exclusão associamos-lhe a designação de social, ou seja, falamos de exclusão da sociedade. O referencial é a sociedade. Mas o que é a sociedade? A sociedade (seja local, nacional, regional ou global) é constituída por um conjunto de sistemas sociais, alguns dos quais poderão ser considerados como básicos ou essenciais.

Embora a amplitude de tal conjunto de sistemas possa depender dos conceitos utilizados, nomeadamente do de cidadania, é comum considerar-se cinco sistemas sociais básicos: social ou das sociabilidades; económico; institucional; espacial; simbólico (Bruto da Costa, 1998; Bruto da Costa et al., 2008).

Deve-se, porém, notar que quer os sistemas sociais básicos considerados, quer os domínios em que foram agrupados, são interdependentes entre si, sobrepondo-se, mesmo, em alguns casos. A falta de recursos, no mínimo, dificultará o acesso ao mercado de bens e serviços, bem como provocará maiores dificuldades no acesso aos sistemas prestadores de serviços, mesmo aos que estão total ou parcialmente protegidos.

21 Se essa situação de falta de recursos - ligada ao domínio económico - se ficar a dever a uma situação de desemprego, por exemplo, as implicações poder-se-ão estender também ao domínio social, afectando as relações sociais do indivíduo; ao domínio das referências, através das perdas ao nível da identidade social; e ao domínio territorial, podendo implicar porventura a mudança para uma área "excluída"; além das referidas dificuldades no domínio institucional. 

entre o acesso dos indivíduos a estes sistemas e a sua integração ao nível dos respectivos domínios. Neste, como noutros campos, dever-se-á privilegiar uma perspectiva holista.

do mais, não se trata somente da questão de ter ou não ter acesso aos sistemas, mas também do grau desse acesso, o que configura graus maiores ou menores de integração e, concomitantemente, graus maiores ou menores de exclusão.

exclusão pode ser considerada como um processo, que vai de formas mais superficiais de exclusão para formas e graus mais profundos e abrangentes de exclusão. A forma extrema corresponderá à situação de ruptura com todos os sistemas sociais básicos, situação extrema que é mais facilmente associada, por exemplo, à situação das pessoas sem-abrigo, no sentido estrito das pessoas sem-tecto (categorias 1 e 2 da tipologia europeia de pessoas sem-abrigo e exclusão habitacional - ETHOS) ${ }^{3}$.

Da mesma forma, o grau de integração nos diferentes sistemas e domínios pode variar, pelo que o indivíduo pode estar integrado a uns níveis e excluído a outros. A uma boa ou razoável integração em termos económicos pode não corresponder uma equivalente integração a nível institucional. E se a integração no domínio social pode ser apercebida pelos sujeitos como positiva, tal não é contraditório com o verificar-se uma exclusão a nível territorial.

\section{Da análise das dinâmicas à estrutura da pobreza na sociedade portuguesa}

Estabelecidos, ainda que de forma necessariamente breve, alguns pressupostos acerca da pobreza e da exclusão social, importa agora equacionar um conjunto de resultados que permitem estabelecer uma imagem mais quantificada e concreta sobre a prevalência efectiva de situações de pobreza na sociedade portuguesa.

Os sistemas estatísticos nacional e europeus habituaram-nos já, nos últimos anos, à disponibilização de dados acerca da pobreza. Apesar do hiato sistematicamente existente e que faz que os dados mais recentes distem cerca de dois anos relativamente ao momento em que são disponibilizados, são dados que vão demonstrando proporção de população que, de acordo com o critério definido pelo Eurostat ${ }^{4}$, é considerada, em cada ano, como estando em situação de pobreza ${ }^{5}$.

Tais dados são, contudo, de natureza eminentemente estática, dado conta da situação instantânea em cada ano a que a inquirição diz respeito. $O$ que se apresenta de seguida são dados de natureza dinâmica acerca da pobreza, ou seja, utilizando dados provenientes de diferentes vagas do Painel dos Agregados Domésticos Privados da União Europeia, aplicado a nível europeu até 2001, e que foi entretanto sido substituído pelo Inquérito às Condições de Vida e Rendimento.

29 Estes são, então, dados que permitem caracterizar o fenómeno da pobreza em Portugal de forma longitudinal - entre 1995 e 2000 -, possibilitando aferir resultados que, necessariamente, não são possíveis de obter com a análise de apenas um ano. Optou-se, para efeitos do presente artigo, por organizar os dados num conjunto de oito pontos.

300 primeiro desses pontos é que, durante o período de seis anos analisado, $46 \%$ das pessoas em Portugal e $47 \%$ dos agregados passaram por uma situação de pobreza em 
pelo menos um desses anos. Quer isto dizer que cerca de metade das famílias portuguesas vivem numa situação vulnerável à pobreza, mais grave do que apenas uma «situação de risco», uma vez que passaram de facto pela pobreza em pelo menos um ano.

Isto revela que a pobreza em Portugal é mais extensa do que reflectem as taxas instantâneas referidas a um dado ano, e que têm rondado os $20 \%$, situando-se o último valor disponível, de acordo com os dados de 2009, em 18\% dos indivíduos.

Parece imprescindível dizer que, enquanto problema social e do ponto de vista das políticas, esta deve ser encarada como a verdadeira dimensão da pobreza em Portugal. Esta perspectiva engloba não apenas as pessoas que se encontram persistentemente por vezes ao longo de toda a sua vida - numa situação de pobreza, mas também pessoas cuja situação, embora melhor, é de extrema vulnerabilidade. Incluirá, igualmente, todo um conjunto de pessoas que, habitualmente, se posicionam acima da linha de pobreza mas que, perante determinados condicionalismos, acabam por se situar, em dado momento, abaixo dessa mesma linha.

Importa também salientar que esta conceptualização não altera de forma decisiva a composição da população pobre. De facto, os grupos mais vulneráveis à pobreza mantêm-se ${ }^{6}$. Entre estes está a população idosa, que, à elevada vulnerabilidade à pobreza, associa uma elevada distribuição. Ou seja, do conjunto de população definida como pobre, uma parte substancial é composta por população idosa.

Esta situação encontra eco no facto de, segundo o Eurobarómetro de Fevereiro de 2010, dedicado às percepções dos europeus acerca da pobreza e da exclusão social (Special Eurobarometer $321 / 72.1$ ), quase $60 \%$ dos/as portugueses/as identificar este grupo como particularmente vulnerável.

$\mathrm{O}$ mesmo não acontece, no entanto, relativamente às crianças. A sua notória pouca visibilidade faz que apenas $9 \%$ das pessoas as refiram como um grupo particularmente vulnerável, situação que contrasta em absoluto com os dados que consolidam as crianças como um dos principais grupos em situação de pobreza.

Não sendo titulares de rendimento, as crianças não podem, em sentido estrito, ser consideradas pobres na sua acepção de privação por falta de recursos. A sua situação face à pobreza deriva, pois, tal como outros elementos não titulares de rendimento, da sua integração num agregado, para o qual é estabelecido um determinado valor de rendimento, ainda que esse possa ser igual a zero.

Adicionalmente, pressupõe-se que cada um dos elementos desse agregado usufrui de uma proporção igual desses recursos totais, depois de ponderados pela escala de equivalência. A pobreza infantil, enquanto temática autónoma, tem merecido, aliás, destaque particular da comunidade científica ${ }^{7}$, pelo que não entraremos em pormenor neste ponto.

38 A população desempregada, por seu turno, é identificada por duas em cada três pessoas auscultadas no âmbito do Eurobarómetro. Deve, porém, ser realçado que, apesar de, inegavelmente, se tratar de uma situação de grande vulnerabilidade, apenas cerca de $5 \%$ da população pobre é composta por população desempregada.

Um segundo ponto essencial é que mais de metade (54\%) dos agregados pobres, em pelo menos um ano, esteve na pobreza durante três ou mais anos, e $72 \%$ dos agregados experimentaram a pobreza durante pelo menos dois anos. 
40 Perante valores de tal ordem, não restam dúvidas de que grande parte da pobreza registada, mais do que para uma situação pontual, aponta antes para uma pobreza de carácter persistente. Dito de outra forma, a pobreza em Portugal, mais do que uma realidade conjuntural ou marginal da sociedade portuguesa, assume antes características de um problema social estrutural e extenso.

41 Aliás, e este é o terceiro ponto a assinalar, cerca de uma em cada quinze pessoas residentes no país mantiveram-se em situação de pobreza ao longo dos seis anos considerados. Este é um valor que, se traduzido para a expressão numérica da população do país, remete para um quantitativo de cerca de 700 mil pessoas persistentemente em situação de pobreza. Pessoas cuja existência, muitas vezes desde o nascimento, é caracterizada pela pobreza que, por sua vez e amiúde, caracterizou já também a vida dos seus pais e avós ${ }^{8}$.

42 Do quadro descrito decorre um quarto ponto fundamental. Políticas sociais de combate à pobreza apoiadas na fotografia que, em cada ano, seja possível tirar relativamente à situação do país correm o risco de não conseguir equacionar e enquadrar aspectos fulcrais da problemática que apenas uma análise longitudinal e dinâmica permitem reconhecer.

Como vimos, os valores em torno dos $18 \%$ de pobres em cada ano incluem situações diversas relativamente às quais as abordagens devem também ser diferenciadas. Por outro lado, dificilmente as políticas preconizadas para um cenário de $18 \%$ de pobres serão as mesmas num cenário em que a pobreza caracterize quase metade da população. Da mesma forma, se não forem equacionadas de forma mais ampla e integrada, verão a sua eficácia certamente diminuída no que respeita àqueles cuja situação de pobreza não é passageira nem decorrente de um qualquer acontecimento excepcional nas suas vidas - e que representam, grosso modo, cerca de uma em cada três das pessoas que, em cada ano, são classificadas como pobres.

No contexto de quaisquer políticas sociais que sejam implementadas, é claro - e este é um quinto ponto essencial - que as políticas redistributivas são indispensáveis para o combate à pobreza ${ }^{9}$. Com efeito, cerca de dois em cada cinco agregados alguma vez pobres durante o período de seis anos considerado têm as pensões como principal fonte de rendimento, ao que acrescem outros agregados dependentes de benefícios sociais.

Verifica-se, no entanto, e este é o sexto ponto, que mais de metade dos agregados alguma vez pobres têm como principal fonte o rendimento de trabalho. Embora as medidas redistributivas sejam necessárias para que estes agregados possam vencer a privação, a resolução destas situações de pobreza implica a operacionalização de medidas que ajudem as pessoas a tornar-se auto-suficientes em matéria de recursos.

Trata-se, aqui, não de redistribuição mas de repartição primária do rendimento. Isto tem a implicação importante de situar o combate à pobreza não apenas no âmbito da política social mas também no âmbito da política económica em sentido lato.

É sabido que o combate à precariedade do emprego (quer no que se refere à instabilidade, quer quanto ao baixo nível dos salários) requer, além do mais, o crescimento da produtividade geral da economia e do trabalho em particular. Constatase que cerca de $70 \%$ dos representantes dos agregados pobres em pelo menos um dos anos considerados e que eram trabalhadores por conta de outrem tinham um contrato sem termo. Também se verificou que tinham, maioritariamente, trabalho a tempo 
inteiro. Daqui decorre que a precariedade se situará, em grande medida, ao nível dos salários.

É igualmente sabido que a elevação dos salários é tarefa complexa, que exige tempo e o envolvimento decidido de três tipos de actores: os trabalhadores, incluindo os sindicatos; os empresários (pelo muito que deles dependem as medidas destinadas a aumentar a produtividade ${ }^{10}$ ); e o Estado. O que há a fazer neste domínio está sobejamente identificado. Resta reconhecer que se trata de uma alavanca fundamental do progresso do país, e agir em conformidade. Trata-se de um domínio em que não é possível fazer de mais para se ser eficaz e antecipar, quando possível, a obtenção de resultados.

Um sétimo ponto essencial que deve ser realçado é a forte relação entre o nível de escolaridade atingido pelos pobres e a idade em que começaram a trabalhar, sendo que aquele nível é tanto mais baixo quanto mais cedo as pessoas entraram na vida de trabalho.

50 Este é, sem dúvida, um dos ciclos viciosos da pobreza: o pobre tem baixo nível de educação por ser pobre e é pobre por ter níveis baixos de escolaridade. Por outro lado, outro ciclo que, a partir daqui, se reproduz é o que conduz os portadores de baixos níveis de educação a situações profissionais menos favoráveis. Daqui decorre, em grande medida, que a pobreza persista não só ao longo de toda a vida de uma pessoa, mas também que se verifique uma transmissão intergeracional ${ }^{11}$.

51 Apesar da evolução em termos educativos que, apesar de tudo, se vai registando, o facto de esta derivar de pontos de partida extremamente baixos - em muitos casos, do analfabetismo - faz que a sua expressão tenha de ser francamente relativizada (Bruto da Costa et al., 2008), sobretudo se a isso se juntar a própria evolução societal e das exigências a ela associadas.

O sistema educativo adquire, pois, uma importância fundamental. No entanto, para que esta importância seja consequente, torna-se essencial assegurar às crianças pobres não só o indispensável acesso ao sistema escolar - onde se pode incluir os apoios à família mas também condições para o seu sucesso, ao qual corresponda uma efectiva aquisição de conhecimento e de aptidões.

O oitavo ponto fundamental a assinalar prende-se com o facto de mais de metade dos portugueses continuar a colocar as causas da pobreza no país em factores como a sorte, a inevitabilidade, o fatalismo, ou faltas imputáveis aos pobres, como a preguiça ou a falta de força de vontade. Da mesma forma, $44 \%$ tende a acreditar que "a desigualdade de rendimento é necessária para o desenvolvimento económico".

Os resultados do Eurobarómetro dedicado às percepções dos europeus acerca da pobreza e da exclusão social já citado mostram, ainda, por exemplo, que menos de uma em cada cinco pessoas relaciona a pobreza com a ausência dos "necessários níveis de educação, formação ou competências", tantas quantas as que colocam a responsabilidade nas pessoas por "viverem acima das suas possibilidades". Adicionalmente, apenas 13\% identifica as pessoas com baixos níveis de educação, formação e/ou competências como um grupo particularmente vulnerável à pobreza.

Sabendo-se que uma acção eficaz contra a pobreza, sobretudo pelas mudanças sociais que implica, requer a aceitação, ou pelo menos o consentimento, da sociedade, concluise que, a par do que se faça em matéria de projectos, programas, planos e políticas, é 
necessária uma ampla campanha de esclarecimento e de promoção da justiça social e de solidariedade.

\section{Acção e estruturalidade da pobreza - reflexões para a intervenção}

56 A compreensão dos fenómenos da pobreza e da exclusão social exige, como vimos, a clarificação de um conjunto de conceitos cruciais que nos permitem interpretar a realidade social à luz de determinadas "opções" teóricas. Por outro lado, essa interpretação deverá ser necessariamente sustentada por resultados concretos que, pesem embora algumas limitações de natureza estatística ou metodológica anteriormente referidas, constituem matéria-prima fundamental para uma reflexão séria sobre a pobreza e a exclusão social e sobre as suas implicações ao nível das políticas.

Mas de que forma poderá esse corpo de conhecimento adquirido - e em permanente actualização e aprofundamento - contribuir para uma reflexão ao nível do trabalho de intervenção e dos seus impactos junto das pessoas, dos grupos e dos territórios com os quais se estabelecem diferentes tipos de dinâmicas interventivas?

Procuraremos ao longo desta parte final suscitar alguma reflexão sobre a pertinência de uma abordagem que, partindo do chamado "conhecimento teórico", interpele directamente o trabalho de intervenção social ${ }^{12} \mathrm{em}$ aspectos que consideramos essenciais para informar e qualificar o chamado "trabalho directo" com as populações.

Consciencializar os actores sociais com responsabilidades de intervenção social da importância de clarificar conceitos como pobreza, exclusão social, privação, necessidades ou capacidades constitui, na nossa opinião, uma tarefa fundamental. Senão vejamos.

60 Vimos na primeira parte deste artigo que pobreza pode ser definida como uma situação de privação decorrente da falta de recursos. Neste sentido, a pobreza só poderá ser eficazmente combatida com acções que permitam à pessoa ou à família inverter o processo que conduziu a essa escassez de recursos, ou seja, conseguir autonomamente e de forma considerada "socialmente normal" suprir as suas necessidades.

61 A consciência de que pobreza e privação constituem fenómenos diferentes é fundamental para que seja possível, nomeadamente, ter uma percepção mais clara dos limites - profissionais e organizacionais - da intervenção desenvolvida e a desenvolver e dos resultados desejáveis e legítimos. Identificar limites significa, simultaneamente, ter uma melhor percepção das complementaridades que importa promover no sentido de combater de forma eficaz não apenas a privação (p. ex. através do recurso a bancos de alimentos), mas também a pobreza e a exclusão social (p. ex. reforçando qualificações/competências profissionais, disponibilizando serviços de apoio à infância acessíveis e de qualidade que permitam uma real activação laboral de pessoas com responsabilidades parentais; denunciar/combater a precariedade salarial como um dos principais factores de manutenção dos elevados níveis de pobreza em Portugal).

Ainda ao nível dos conceitos, importa reflectir sobre as consequências para a intervenção social da abordagem baseada no conceito de capacidades, tal como são definidos por Amartya Sen (1999) e que se apresentaram, de forma breve, no início do presente artigo. Sen valoriza não apenas a satisfação das necessidades como condição 
indispensável para combater a privação, mas também a forma como essas necessidades são satisfeitas, conferindo ou não à pessoa as capacidades de que ela necessita para funcionar.

Em primeiro lugar, o enfoque nas necessidades interpela-nos desde logo sobre aquele que deverá ser o centro de qualquer intervenção: a pessoa. Podendo esta afirmação parecer, à primeira vista, demasiado elementar, questionemo-nos seriamente sobre quantas vezes não segue a intervenção a lógica dos recursos disponíveis, muito mais do que as necessidades sentidas e expressas pela pessoa.

Tendo consciência da dimensão de muitos dos obstáculos que se colocam a este nível, parece-nos fundamental que os actores com responsabilidades directas na intervenção social exercitem de forma crítica uma interpelação do(s) contexto(s) em que trabalham, e para o qual muito poderá contribuir uma consciencialização clara de alguns conceitos fundamentais.

Já no que se refere ao conceito de capacidade, Sen parece abrir-nos mais uma porta para que possamos medir o impacto da intervenção desenvolvida. Uma avaliação crítica do trabalho que desenvolvemos deverá permitir-nos perceber se uma determinada aç̧ão contribuiu para satisfazer uma determinada necessidade e se, simultaneamente, conferiu à pessoa a capacidade de que a mesma precisa para que possa, com esse "recurso" acrescido, continuar a manter essa necessidade devidamente satisfeita.

Importa explicitar que não é nosso propósito pôr aqui em causa a importância de se prosseguir com acções ou actividades que tenham por fim último a satisfação de necessidades básicas fundamentais. Parece-nos, contudo, crucial que se promova uma consciência clara, por parte de quem intervém directa ou indirectamente, de que esse tipo de acções, sendo indispensáveis, não se podem esgotar em si mesmas, na medida em que, embora possam resolver a privação, não contribuem para combater a pobreza de forma eficaz.

67 Esta consciência crítica sobre as potencialidades e os limites do trabalho que se desenvolve neste domínio é tanto mais importante quanto, como referido anteriormente, a pobreza é, de facto, um fenómeno multidimensional cuja resolução convoca necessariamente uma pluralidade de respostas e de desafios que, estando centrados sobre as necessidades das pessoas e das famílias ${ }^{13}$ e sobre a promoção das suas capacidades, exige uma complementaridade de respostas e não uma sobreposição e concentração de respostas/recursos idênticos.

Se os desafios teóricos colocados pela adopção de um determinado conceito de pobreza nos parecem determinantes no sentido de repensar as estratégias de intervenção ao nível do trabalho social, também o conceito de exclusão social merece uma atenção particular pela referência explícita que faz à sociedade como referencial fundamental. A exclusão é um problema social que afecta indivíduos e grupos que se vêem privados no todo ou em parte - do acesso àquilo que designámos por sistemas sociais.

Se as relações entre as pessoas e estes sistemas se materializam no quotidiano - e, neste sentido, também os próprios mecanismos de exclusão -, nem sempre a proximidade quotidiana entre organizações, profissionais e populações parece promover necessariamente uma maior visibilidade/compreensão desses mecanismos.

70 Com efeito, importa questionar o excessivo enfoque na diversidade e complexidade das experiências individuais nessa interacção entre clientes e organizações/profissionais, em detrimento de uma análise dos mecanismos que, a um nível meso e mesmo macro, 
lhes estão subjacentes. A proximidade com as populações só é, de facto, uma mais-valia importante no trabalho social se não se limitar a um acumular de conhecimento acrítico e se esse conhecimento/contacto directo puder influenciar processos de mudança pessoal/familiar, mas também organizacional, e, não menos importante, alertar para a necessidade de mudanças de natureza societal indispensáveis no combate à exclusão social.

71 Um outro aspecto que nos parece fundamental neste potencial de conhecimento que poderá advir desta relação directa com as pessoas no âmbito do trabalho social diz respeito à identificação não só de situações de pobreza, mas também dos processos que conduzem a estas situações. Com efeito, importa recordar a importância da adopção de uma abordagem dinâmica ao fenómeno da pobreza.

Os dados apresentados anteriormente sobre a caracterização da pobreza em Portugal ao longo de um período de seis anos permitiram-nos uma reflexão imprescindível sobre a verdadeira dimensão da pobreza na nossa sociedade, com consequências directas ao nível das políticas.

Da mesma forma, a adopção desta perspectiva dinâmica na análise dos fenómenos da pobreza e da exclusão social seria igualmente fundamental ao nível do conhecimento produzido pelo contacto directo com as populações. A proximidade deverá servir não apenas para uma caracterização das situações, mesmo que feita em vários tempos, mas sobretudo para compreender as dinâmicas subjacentes à evolução das situaç̃oes pessoais e familiares e, neste sentido, identificar não apenas as microcausalidades individuais, mas também as macrocausalidades estruturais.

Clarificar conceitos, adquirir um conhecimento actualizado e abrangente sobre a realidade da pobreza e da exclusão social, quer ao nível nacional, quer num contexto europeu mais lato, constituem, na nossa opinião, instrumentos fundamentais para uma intervenção que se pretende interpelativa e crítica da realidade social.

Por outro lado, importa não esquecer que a pobreza, em Portugal, continua ainda ${ }^{14}$ a ser percepcionada como um fenómeno em que a responsabilidade das próprias pessoas pobres e a sua envolvente familiar parecem constituir importantes factores explicativos, contrariamente à importância atribuída aos níveis de educação e qualificação. Em Portugal, as percepções sobre a pobreza ${ }^{15}$ e o conhecimento estatisticamente fundamentado encontram-se de facto ainda longe de uma sintonização adequada.

Neste contexto, importa ter consciência de que as percepções que se constroem sobre estes fenómenos sociais são transversais à sociedade, abrangendo naturalmente aquelas e aqueles que no quotidiano têm uma responsabilidade directa no trabalho com as populações mais atingidas pela pobreza e a exclusão social. A investigação e os seus actores deverão, pois, ter uma responsabilidade acrescida no sentido de promover espaços de reflexão teórica que não se esgotem em si próprios. Devem conseguir, além disso, interpelar directamente outros níveis de abordagem da realidade social, constituindo-se como instrumentos úteis de sensibilização e consciencialização das potencialidades e dos limites, nomeadamente, da intervenção social no domínio da pobreza e da exclusão social. 


\section{BIBLIOGRAFIA}

AAVV (2010), Estudo sobre a percepção da pobreza em Portugal. Algumas considerações e recomendações, Lisboa, REAPN/AI.

ALBUQUERQUE, J., et al. (2006), Medidas de pobreza e exclusão social em Portugal, Documento de trabalho, Lisboa, MTSS/DGEEP.

ALMEIDA, J. F., et al. (1992), A exclusão social - factores e tipos de pobreza em Portugal, Oeiras, Celta Editora.

ALVES, N. (2009), Novos factos sobre a pobreza em Portugal, Boletim Económico - Primavera, Lisboa, Banco de Portugal.

AMORE, K., et al. (no prelo) "The ETHOS definition and classification of homelessness: an analysis", European Journal of Homelessness, 5.

BAPTISTA, I., et al. (1995), A pobreza no Porto: representações sociais e práticas institucionais, Porto, Cadernos REAPN, 1.

BASTOS, A., et al. (2008), Um olhar sobre a pobreza infantil. Análise das condições de vida das crianças, Coimbra, Almedina.

BASTOS, A., et al. (2011), Números com esperança. Abordagem estatística da pobreza infantil em Portugal, Coimbra, Almedina.

BRUTO DA COSTA, A., et al. (1985), A pobreza em Portugal, Lisboa, Cáritas.

BRUTO DA COSTA, A. (1998), Exclusões sociais, Lisboa, Gradiva/Col. Fundação Mário Soares.

BRUTO DA COSTA, A., et al. (2008), Um olhar sobre a pobreza: vulnerabilidade e exclusão social no Portugal contemporâneo, Lisboa, Gradiva.

CARMO, H. (coord.) (1996), Exclusão social: rotas de intervenção, Lisboa, ISCSP.

EDGAR, B. (2009), European review of statistics on homelessness, Bruxelas, FEANTSA/EOH.

FERREIRA, L. V. (1997), Teoria e metodologia da medição da pobreza, Tese de doutoramento, Lisboa, ISEG-UTL.

FERREIRA, L. V. e C. Rodrigues (2002), Distribuição do rendimento, pobreza e papel das políticas redistributivas, Porto, CCRN.

GUERRA, I. (2002), Fundamentos e processos de uma sociologia da aç̧ão: o planeamento em Ciências Sociais, Cascais, Principia.

HESPANHA, P., et al. (2007), Famílias pobres: desafios à intervenção social, Lisboa, Climepsi.

INE (2010), Sobre a pobreza, as desigualdades e a privação material em Portugal, Lisboa, INE.

LABBENS, J. (1969), Le Quart Monde, Pierrelaye, Editions Science et Service.

MACHADO, C., et al. (2007), “A privação em Portugal (1995-2001)” Revista Sociedade e Trabalho, 30, Lisboa, MTSS/DGEEP.

PEREIRINHA, J. A. (2008), Política social: fundamentos da actuação das políticas públicas, Lisboa, Universidade Aberta.

RODRIGUES, C. F. (2008), Distribuição do rendimento, desigualdade e pobreza: Portugal nos anos 90, Coimbra, Almedina. 
RODRIGUES, C. F., et al. (2011), Desigualdades sociais - Conclusões preliminares do estudo Desigualdade em Portugal, Lisboa, Fundação Francisco Manuel dos Santos.

RODRIGUES, F. (org.) (2003), Acção social na área da exclusão social, Lisboa, Universidade Aberta.

SEN, A. (1999), Development as Freedom, Nova Iorque, Anchor Books.

SPECIAL EUROBAROMETER 321 / 72.1.

TOWNSEND, P. (1987), “Deprivation”, Journal of Social Policy, 16 (2), pp. 125-146.

\section{NOTAS}

1. Para uma reflexão recente sobre a temática das desigualdades em Portugal cf., por exemplo, Rodrigues et al., 2011.

2. Para um aprofundamento da discussão sobre a problemática da privação cf., por exemplo, Ferreira, 1997; Rodrigues, 2008; Bruto da Costa et al., 2008; INE, 2010.

3. Para um aprofundamento desta questão e debate subsequente ver Edgar, 2009 e Amore et al. (no prelo).

4. São consideradas pobres as pessoas pertencentes a agregados cujo rendimento seja inferior a $60 \%$ da mediana dos rendimentos por adulto equivalente, sendo este conceito definido através da escala da OCDE modificada. Esta escala define que ao primeiro adulto do agregado (definido como tendo 16 ou mais anos) corresponde o ponderador 1 , a cada adulto adicional o ponderador de 0,5 e a cada criança (com menos de 16 anos) o valor de 0,3 .

5. Para uma discussão mais aprofundada relativamente a definições de linhas de pobreza e escalas de equivalência, cf. Albuquerque et al., 2006; Bruto da Costa et al., 2008; INE, 2010.

6. Veja-se, por exemplo, Bruto da Costa et al., 1985; e Almeida et al., 1992.

7. Cf., por exemplo, Bastos et al., 2008, 2011.

8. Situação que já o primeiro estudo sobre a problemática da pobreza em Portugal relevava (Bruto da Costa et al., 1985).

9. Como aliás tem sido referido por outros autores, nomeadamente Ferreira e Rodrigues, 2002; e Pereirinha, 2008.

10. Veja-se, a este propósito, os resultados de um estudo levado a cabo pela multinacional McKinsey, segundo o qual Portugal ocupava o antepenúltimo lugar em termos de qualidade de gestão das empresas nacionais, o que, em muito, "ajuda a justificar a fraca competitividade da economia nacional e as dificuldades de crescimento verificadas nos últimos anos» (in Diário Económico 16/07/2007, citado em http://diariodigital.sapo.pt/dinheiro_digital7news.asp? section_id=3\&id_news=83727).

11. Ver, por exemplo, Rodrigues, 2008; e Alves, 2009.

12. Ver, a este respeito, por exemplo, Carmo (coord.) (1996); Guerra, 2002; e Rodrigues (org.) (2003).

13. Para uma melhor compreensão do papel da intervenção social junto de famílias em contextos socioeconomicamente desfavorecidos ver, por exemplo, Hespanha et al., 2007.

14. Pese embora a evolução recente registada ao nível das percepções dos grupos mais atingidos pela pobreza e respectivas causas, no sentido de um peso acrescido dos factores de natureza societal, face aos factores individuais (AAVV, 2010).

15. A análise das percepções sobre a pobreza em Portugal tem sido objecto de pesquisa autónoma desde meados dos anos 90 (cf. por exemplo, Baptista et al., 1995; AAVV, 2010). 


\section{RESUMOS}

O presente artigo sistematiza algumas das principais conclusões da publicação Um olhar sobre a pobreza: vulnerabilidade e exclusão social no Portugal contemporâneo, de que os autores deste artigo partilham a autoria, alargando, simultaneamente, o debate aos desafios que se colocam à intervenção. $O$ texto encontra-se estruturado em quatro partes principais. Na primeira procurase clarificar o conceito de pobreza e a sua relação com outros conceitos relevantes, alargando-se a discussão, na segunda parte, ao conceito de exclusão social. Na terceira parte, sistematiza-se um conjunto de conclusões relativamente à estruturalidade da pobreza na sociedade portuguesa, tendo por base a análise dinâmica de seis vagas do Painel dos Agregados Domésticos Privados da União Europeia. Finalmente, na quarta parte, recupera-se alguns dos elementos de análise, reflectindo sobre as suas possíveis implicações para a intervenção social.

This article systematises some of the main conclusions of the book Um olhar sobre a pobreza: vulnerabilidade e exclusão social no Portugal contemporâneo, of which the authors of the article share authorship. Additionally it debates the challenges such conclusions pose to social intervention. The text is structured in four main parts. The first aims at clarifying the concept of poverty and its connection with other relevant concepts. The second part widens this discussion to the concept of social exclusion. The third part draws a set of conclusions regarding the structural character of poverty in the Portuguese society, based on the dynamic analysis of six waves of the European Community Household Panel. Finally, in the fourth part, some of the elements of analysis are revisited and analysed under the scope of their possible implications for social intervention.

\section{ÍNDICE}

Keywords: poverty, social exclusion, structure, social intervention

Palavras-chave: pobreza, exclusão social, estruturalidade, intervenção social

\section{AUTORES}

\section{PEDRO PERISTA}

Investigadores no CESIS - Centro de Estudos para a Intervenção Social, pedro.perista@cesis.org

\section{ISABEL BAPTISTA}

Investigadores no CESIS - Centro de Estudos para a Intervenção Social, isabel.baptista@cesis.org 